\title{
Myonecrosis in a horse after an intramuscular injection of menbutone ${ }^{1)}$
}

\author{
MALWINA SŁOWIKOWSKA, NATALIA SIWIŃSKA, AGNIESZKA ŻAK, \\ HIERONIM BOROWICZ, KRZYSZTOF KUBIAK, ARTUR NIEDŹWIEDŹ
}

\begin{abstract}
Department of Internal Medicine and Clinic of Diseases of Horses, Dogs and Cats, Faculty of Veterinary Medicine, Wrocław University of Environmental and Life Sciences, PI. Grunwaldzki 47, 50-366 Wrocław, Poland
\end{abstract}

\section{Słowikowska M., Siwińska N., Żak A., Borowicz H., Kubiak K., Niedźwiedź A. Myonecrosis in a horse after an intramuscular injection of menbutone}

\section{Summary}

Myonecrosis after intramuscular injections is not common, but may be life-threatening. This case report describes myonecrosis following an accidental intramuscular injection of menbutone. A three-year-old bay French Trotter stallion with a history of weak appetite and colic lasting ten days was treated by a field veterinarian. During the course of treatment, he was given paraffin oil and antihelminthics orally, antispasmodics, analgesics, steroids and antibiotics intravenously, as well as choleretics intramuscularly. The horse was apathetic and weak with a "tucked up" abdomen and had grade 2 ataxia, according to Mayhew's grading system. The patient had a swollen neck on both sides and a swelling of the right front limb and the carpal area of the left front limb. The neck edema was painful and warm. The neck area was prepared and punctured; a malodorous fluid was obtained for cytology. In the material obtained, there were anaerobic rod bacteria diagnosed as Clostridium spp. Surgical fenestration and debridement were performed. The wounds were cleaned every day. The horse was given antibiotics, nonsteroidal antinflammatory drugs, fluids and gastroprotectives. After five weeks of intensive care, the condition of the horse stabilized, and significant improvement was observed. Myonecrosis may be a rare life-threatening complication following intramuscular injections or wound contamination. To the authors' best knowledge, this is the first published report of myonecrosis after menbutone injections in the horse.

Keywords: Clostridial myonecrosis, intramuscular injections, menbutone

Menbutone or genabilic acid is used to stimulate the function of the gastrointestinal tract and increase the secretion of bile, as well as gastric and pancreatic juice (9). It is used in hepatic insufficiency or in equine colic. Drugs containing menbutone are registered for use in Poland in farm animals, horses and dogs. In cattle, calves, sheep and dogs, they are administered intramuscularly or intravenously. Pigs and piglets receive the drugs in the form of intramuscular injections, whereas horses receive them as slow intravenous injections. In horses, this drug may be mistakenly injected intramuscularly.

In 1996, the European Agency for the Evaluation of Medicinal Products (EMEA) noted muscle necrosis after menbutone intramuscular injections in calves and pigs. Muscle necrosis, hemorrhage and edema were reported three days after injections in calves. In another study, a necropsy 28 days after menbutone injections

\footnotetext{
1) This case was presented in 2016 as a poster at the international conference "Nowości w chorobach wewnętrznych koni" in Wrocław, Poland, and will be presented in 2018 at WEVA in Beijing, China.
}

in pigs revealed a well-defined area of necrotic muscle tissue with fibrous or granulation tissue that did not heal (9).

Infectious diseases of the muscular system can be bacterial, viral, fungal or parasitic $(1,8)$. Bacterial myositis in horses can be caused by a variety of Clostridium spp., including Cl. septicum, Cl. perfringens, $\mathrm{Cl}$. novyi, Cl. chauvoei, $\mathrm{Cl}$. fallax, $\mathrm{Cl}$. sordelli $(7,10,11,13,15,18-20,22)$. Myonecrosis/myositis following an intramuscular injection is not influenced by the injection technique (6). Other causes of myonecrosis include puncture wounds (19), trauma (11) and wound contamination with dirt or during surgery (5).

\section{Case presentation}

A three-year-old bay French Trotter stallion with a history of a lack of appetite and colic lasting ten days was referred to the Clinic of Diseases of Horses, Dogs and Cats at the Faculty of Veterinary Medicine at the Wrocław University of Environmental and Life Sciences. The horse had previously been treated at the stable by a field veterinarian and 


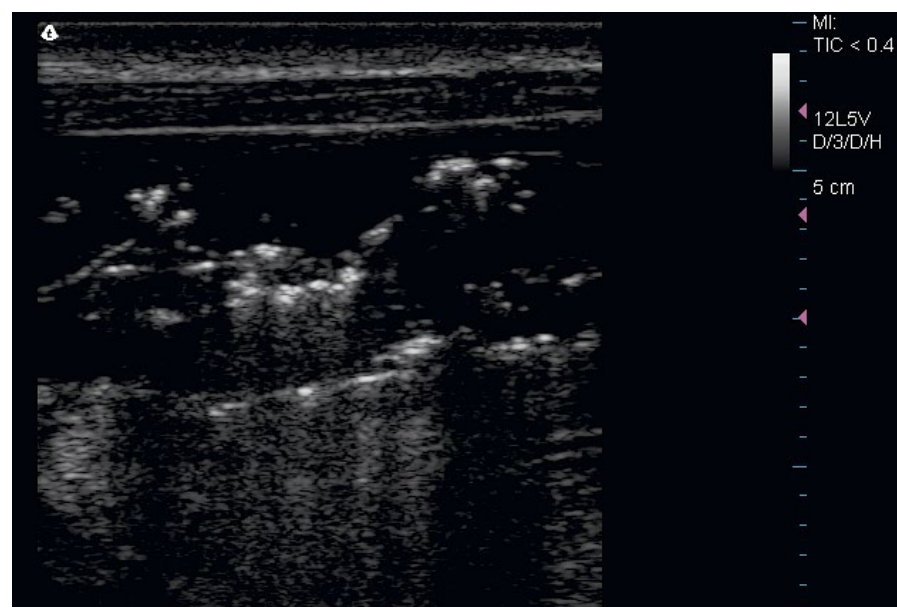

Fig. 1. An ultrasound view of the swollen neck with a large amount of fluid and gas

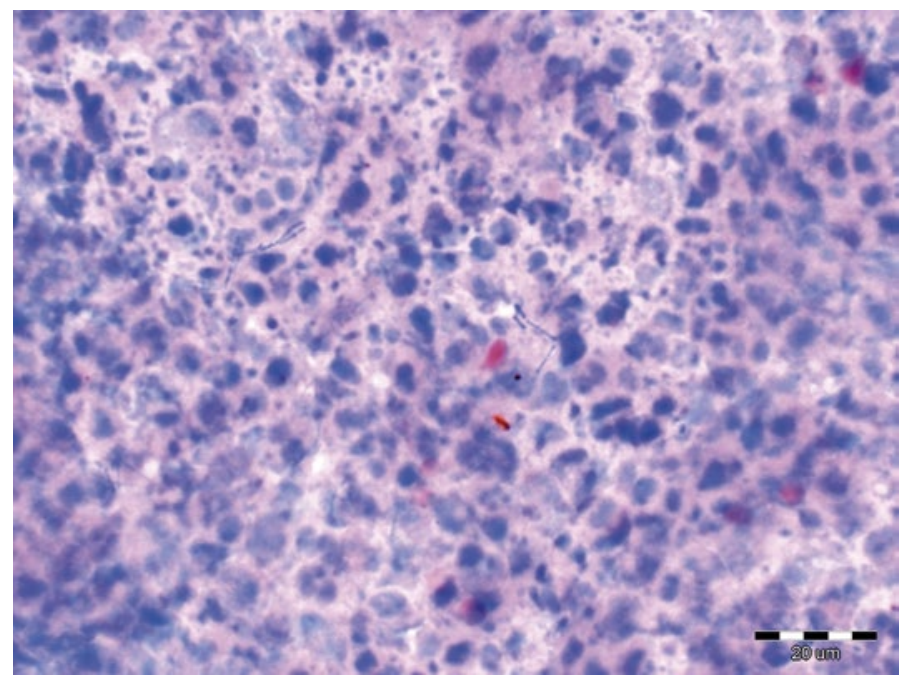

Fig. 3. Rod bacteria in the fluid obtained from the neck area

received paraffin oil and antihelminthics per os, antispasmodic drugs, analgesics, steroids, antibiotics intravenously and choleretics (menbutone) intramuscularly. On admission, the vitals of the horse were recorded. The horse had a heart rate of 40 beats per minute, a respiration rate of 40 breaths per minute and a temperature of $38^{\circ} \mathrm{C}$. The animal was examined neurologically because of its abnormal behavior. It was apathetic, weak and had a "tucked up" abdomen silhouette. It also had grade 2 ataxia, according to Mayhew's grading system. The horse had difficulty walking in tight circles. It walked backwards unwillingly, but without any abnormalities. There were no cranial nerve deficits. There was no anal reflex, which led to an open anus. The test for equine herpesvirus was negative.

Due to colic symptoms, the gastrointestinal tract was examined. The patient was dehydrated. The capillary refill time was three seconds. Small colon impaction was diagnosed during the rectal examination. There was no reflux through the naso-gastric tube. Blood samples for biochemical assays and a hemogram were collected from the jugular vein. The results revealed an elevated level of aspartate transferase (1576 U/1, reference range 205-555 $\mathrm{U} / \mathrm{l})$, alanine aminotransferase (102 U/l, reference range 3-25 U/1), creatine kinase (7706 U/1 reference range 90-565 $\mathrm{U} / \mathrm{l})$, total bilirubin (113 umol/1, reference range 13.7-25.6

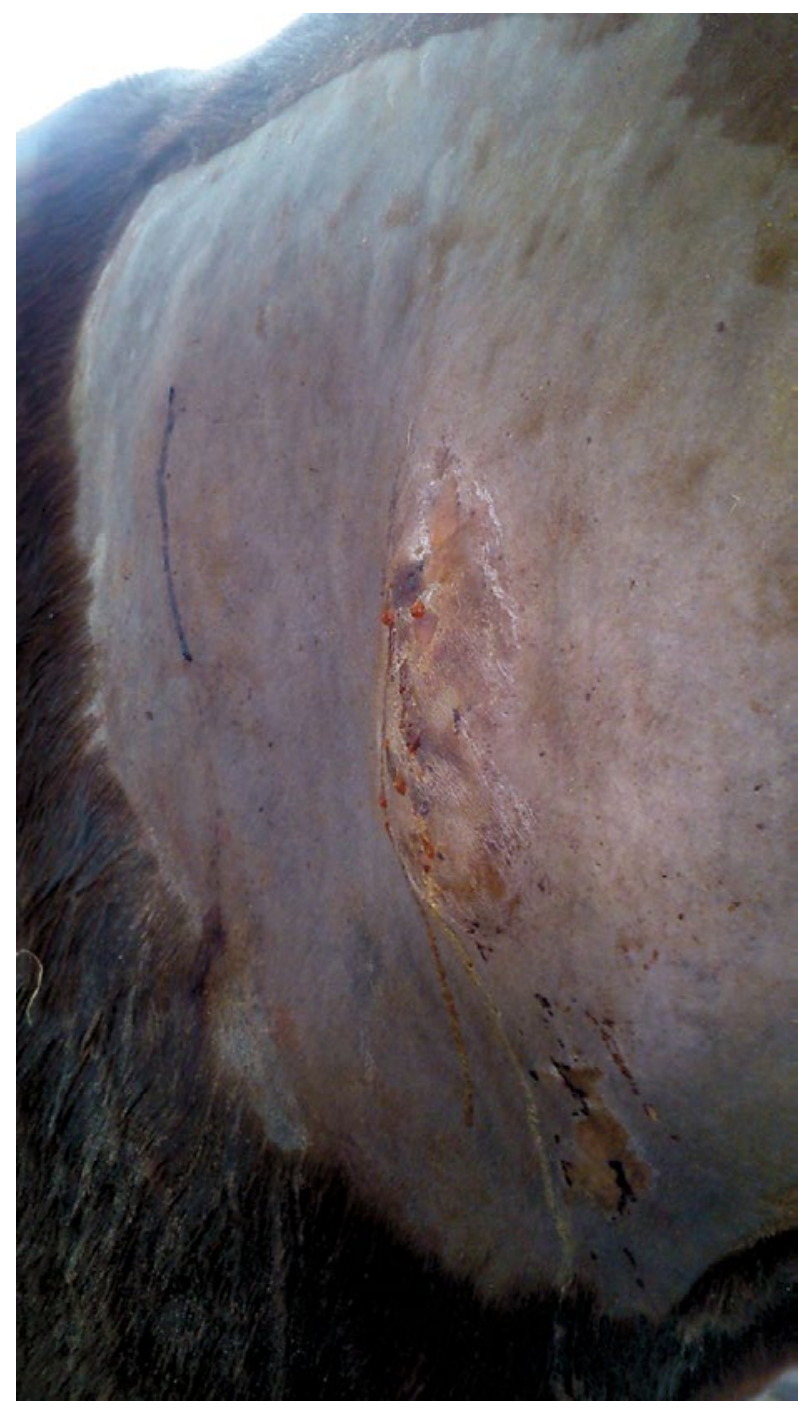

Fig. 2. The swollen neck area

umol/1), serum bile acids (20.4 umol/1, reference range $0-12 \mathrm{umol} / \mathrm{l})$, fibrinogen $(3,79 \mathrm{~g} / \mathrm{l}$, reference range 1-3.75 $\mathrm{g} / \mathrm{l})$ and low levels of magnesium $(0.59 \mathrm{mmol} / 1$, reference range $0.7-1.15 \mathrm{mmol} / \mathrm{l})$, iron $(8.4 \mathrm{umol} / \mathrm{l}$, reference range $13.1-25.1 \mathrm{umol} / \mathrm{l})$, sodium $(122.3 \mathrm{mmol} / \mathrm{l}$, reference range $139.1-156.5 \mathrm{mmol} / \mathrm{l})$ and potassium $(2.54 \mathrm{mmol} / 1$, reference range $3.5-4.7 \mathrm{mmol} / \mathrm{l}$ ). The horse was treated with analgesics, an intravenous fluid therapy and vitamins.

The patient had a swollen neck (on both sides), which was painful and warm. In addition, there was edema of the right front limb and of the carpal area of the left front limb. The animal had an increased appetite, but could not lower its head to eat from the ground. After treating the colic, the horse was fed small portions. An ultrasound of the swollen neck was performed, and a large amount of fluid and gas was noted between muscle groups. An antibacterial therapy was administered, which consisted of gentamycin given intravenously for seven days (at a dose of $6.6 \mathrm{mg}$ per $\mathrm{kg}$ of body weight, once a day - SID), followed by enrofloxacin given orally for 14 days (at a dose of $7.5 \mathrm{mg}$ per kg of body weight, SID) and metronidazole given orally for 27 days (at a dose of $15 \mathrm{mg}$ per $\mathrm{kg}$ of body weight, twice a day - BID). The horse also received probiotics and, for gastric protection, omeprazole orally. Anti-inflammatory therapy included flunixin meglumine administered intravenously for five days 

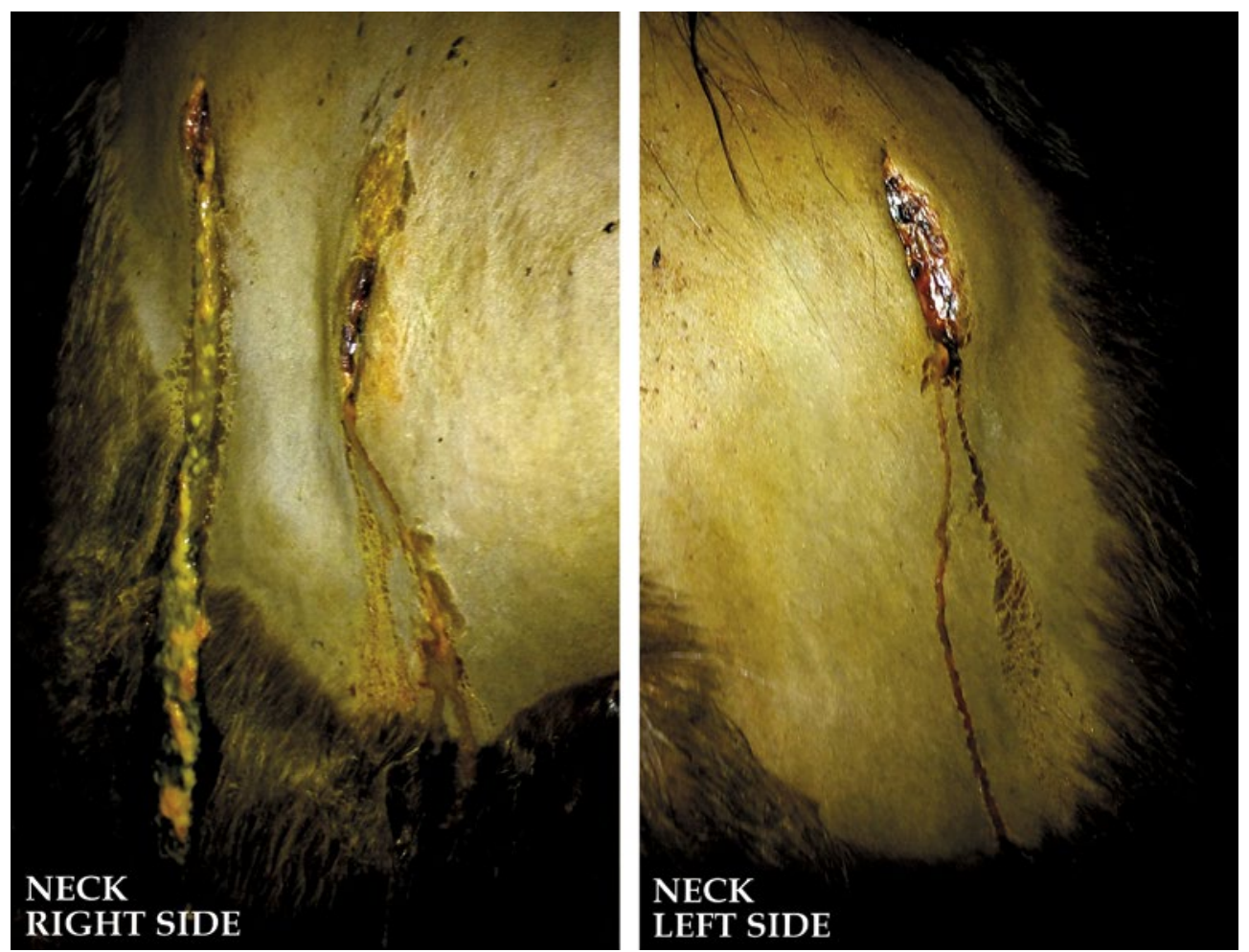

Myonecrosis after intramuscular injections is uncommon, but has been noted after the administration of certain drugs, such as flunixin meglumine $(2,4,18,19)$, ivermectin $(16,22)$, antihistamines $(4,18$, $24)$, phenylbutazone $(18,19)$, hyoscine (7), dipyrone $(7,18$, $24)$, vitamin B $(4,13,18,22)$, vitamin complex (10), vitamin $\mathrm{E}$ and selenium (4), selenium (18), iron (18), aminopropazine (19), synthetic prostaglandins $(20,22)$, xylazine (14), epinephrine (18), rabies vaccine (18), influenza/rhinopneumonitis vaccine (18) and dexamethasone (18).

To the authors' best knowledge, this is the first report of myonecrosis after a menbutone injection in the horse to date. Menbutone is registered in Poland with indications

Fig. 4. The appearance of the wounds before daily cleaning

(at a dose of $1.1 \mathrm{mg}$ per $\mathrm{kg}$ of body weight SID) followed by phenylbutazone given orally (at a dose of $2.2 \mathrm{mg}$ per $\mathrm{kg}$ of body weight BID) for the next 14 days.

The neck area was prepared for a puncture. Malodorous fluid was obtained for cytology, and 1.5 liters of the fluid were evacuated from the three puncture sites. The fluid contained anaerobic rod bacteria, identified as Clostridium spp. For economic reasons, no further tests to differentiate between Clostridium species were performed. Surgical fenestration and debridement were performed on both sides of the neck, during which three liters of fluid were evacuated. The procedure was carried out on the standing horse sedated with detomidine and butorphanol. The wounds were cleaned every day with an isotonic $\mathrm{NaCl}$ fluid, hydrogen peroxide, a povidone-iodine and a metronidazole solution (for the first five days). Oxygen therapy was also used. Despite rigorous wound management for the first three weeks, a significant amount of fluid was evacuated from the neck every day. Hence, a mixture of ether and iodoform was introduced. The horse was very cooperative during wound cleaning. After a two weeks stall confinement, controlled hand-walking 2-3 times per day was initiated. During the course of the treatment, the horse developed colic, which was managed pharmacologically.

After five weeks of intensive care, the condition of the horse stabilized, and significant improvement was observed. The animal was discharged and monitoring instructions were given to the owner.

\section{Conclusions}

Clostridial myonecrosis may also be described as clostridial myositis $(1,6,14)$, clostridial cellulitis $(6$, 22 ), gas-edema disease (7) or malignant edema (15, 19). for use by slow intravenous injections in horses with colic symptoms caused by atonia or obstruction of the gastrointestinal tract and hepatic dysfunction (toxemia, convalescence period after serious colic, infectious diseases, surgery procedures). The drug may be inadvertently used intramuscularly, as in this case. Another similar drug containing clanobutin, with similar therapeutic indications, is registered in Poland and may be administered intravenously and intramuscularly in horses.

Clinical signs of myositis include depression, an increased internal temperature, a prolonged capillary refill time, muscle swelling, lameness, gas crepitation and sudden death $(1,12,19)$. Other reported changes include tachycardia, a stiff gait, dehydration, decreased or absent borborygmi, depression and inappetence $(12,17,19)$. The presence of myositis in the neck muscles may contribute to some signs of ataxia. In the present case, however, the horse was weak and ataxic due to food depravation caused by pain during neck bending.

The formation of emphysema in the area of a recent injection should alert the veterinarian to a diagnosis of myonecrosis. If a presumptive diagnosis of myonecrosis is made, proper treatment is critical for the survival of the animal (17). The animal is most likely to survive with a $\mathrm{Cl}$. perfringens infection. Survival is less likely in the case of an infection with other species of Clostridium (12, 17-19). The introduction of clostridial organisms into muscles may take place during intramuscular injections or through open wounds (6, $12)$. In some colic patients, spores may enter from the gastrointestinal tract (6). One study also found dormant 
clostridial spores in equine skeletal muscles, which were isolated from 10 out of 52 horses (23).

An aggressive pharmacological and surgical therapy is essential in the treatment of presumptive cases of myonecrosis $(1,12,17,19)$. Medical treatment consists of antimicrobial treatment, analgesia, anti-inflammatory and supportive care in the form of intravenous fluids $(1,12,17,19)$. If possible, intramuscular injections should be avoided. Antibiotics should be administered intravenously and orally. Penicillin is usually administered as a first-line antibiotic, although recent research suggests that it is not as effective as expected (21). Metronidazole given intravenously is a better first-choice antimicrobial drug (21). In our study, we decided to use gentamycin intravenously, enrofloxacin orally and metronidazole orally. Metronidazole was not administered intravenously for economic reasons. However, for the first five days after surgical management of the wound, it was flushed with an injectable solution of metronidazole.

Surgical fenestration and/or debridement of necrotic tissue is essential in the treatment of myonecrosis (12). It provides oxygenation, reduces swelling and makes it possible to clean the affected areas and to administer topical treatment (17). In humans, some reports advise the use of hyperbaric oxygen therapy as an adjunctive treatment $(3,12)$. The formation of granulation tissue and wound healing may be long and may leave scars $(12,17)$. The owner should be warned of this possible outcome as well as of the high mortality and high costs of proper treatment.

Myonecrosis is an uncommon life-threatening condition in horses and may result from inadvertent intramuscular injections. It is impossible to completely eliminate intramuscular injections, but this route should be avoided if other forms of drug administration are available.

\section{References}

1.Adam E. N., Southwood L. L.: Surgical and traumatic wound infections, cellulitis, and myositis in horses. Vet. Clin. North Am. Equine Pract. 2006, 22, 335-361.

2. Anderson F. L., Secombe C. J., Lester G. D.: Clostridial myonecrosis, haemolytic anaemia, hepatopathy, osteitis and transient hypertrophic cardiomyopathy after intramuscular injection in a Thoroughbred gelding. Aust. Vet. J. 2013, 91, 204-208.

3. Bakker D. J.: Clostridial myonecrosis (gas gangrene). Undersea Hyperb. Med. 2012, 39, 731-737.

4. Breuhaus B. A., Brown C. M., Scott E. A., Ainsworth D. M., Taylor R. F.: Clostridial muscle infections following intramuscular injections in the horse. J. Eqine Vet. Sci. 1983, 3, 42-46.

5. Brook I.: Microbiology and management of soft tissue and muscle infections. Int. J. Surg. 2008, 6, 328-338.

6. Brown C. M., Kaneene J. B., Walker R. D.: Intramuscular injection techniques and the development of clostridial myositis or cellulitis in horses. J. Am. Vet. Med. Assoc. 1988, 193, 668-670.

7. Coloe P. J., Ireland L., Vaudrey J. C.: Clostridium fallax as a cause of gas-oedema disease in a horse. J. Comp. Pathol. 1983, 93, 597-601.

8. Crum-Cianflone N. F.: Bacterial, fungal, parasitic, and viral myositis. Clin. Microbiol. Rev. 2008, 21, 473-494.

9. EMEA: Committee for veterinary medicinal products. Menbutone. Summary report. The European Agency for the Evaluation of Medicinal Products Veterinary Medicine Evaluation Unit 1996, EMEA/MRL/106/196-FINAL.
10. Farias L. D., Azevedo Mda S., Trost M. E., De La Corte F. D., Irigoyen L. F., de Vargas A. C.: Acute myonecrosis in horse caused by Clostridium novyi type A. Braz. J. Microbiol. 2014, 45, 221-224.

11. Hagemoser W. A., Hoffman L. J., Lundvall R. L.: Clostridium chauvoei infection in a horse. J. Am. Vet. Med. Assoc. 1980, 176, 631-633.

12. Jeanes L. V., Magdesian K. G., Madigan J. E., Meagher D.: Clostridial Myositis in Horses. Comp. Cont. Edu. Pract. Vet. 2001, 23, 577-587.

13. MacKay R. J., Carlson G. P., Hirsh D. C.: Clostridium perfringens Associated with a Focal Abscess in a Horse. J. Am. Vet. Med. Assoc. 1979, 175, 71-72.

14. May K. A., Cheramie H. S., Howard R. D., Duesterdieck K., Moll H. D., Pleasant R. S., Pyle R. L.: Purulent pericarditis as a sequela to clostridial myositis in a horse. Equine Vet. J. 2002, 34, 636-640.

15. Murphy D. B.: Clostridium chauvoei as the cause of malignant edema in a horse. Vet. Med. Small Anim. Clin. 1980, 75, 1152-1154.

16. Nation P. N., Frelier P. F., Schoonderwoerd M.: Clostridial Myositis Following Ivermectin Administration. Can. Vet. J. 1983, 24, 295.

17. Peek S. F., Semard S. D.: Clostridial myonecrosis in horses. Equine Vet. Edu. 2002, 14, 163-168

18. Peek S. F., Semrad S. D., Perkins G. A.: Clostridial myonecrosis in horses (37 cases 1985-2000). Equine Vet. J. 2003, 35, 86-92.

19. Rebhun W. C., Shin S. J., King J. M., Baum K. H., Patten V.: Malignant edema in horses. J. Am. Vet. Med. Assoc. 1985, 187, 732-736.

20. Reef V. B.: Clostridium perfringens cellulitis and immune-mediated hemolytic anemia in a horse. J. Am. Vet. Med. Assoc. 1983, 182, 251-254.

21. Stevens D. L., Maier K. A., Laine B. M., Mitten J. E.: Comparison of clindamycin, rifampin, tetracycline, metronidazole, and penicillin for efficacy in prevention of experimental gas gangrene due to Clostridium perfringens. J. Infect. Dis. 1987, 155, 220-228.

22. Valberg S. J., McKinnon A. O.: Clostridial Cellulitis in the Horse: A Report of Five Cases. Can. Vet. J. 1984, 25, 67-71.

23. Vengust M., Arroyo L. G., Weese J. S., Baird J. D.: Preliminary evidence for dormant clostridial spores in equine skeletal muscle. Equine Vet. J. 2003, 35 , 514-516.

24. Westman C. W., Traub J. L., Schroeder W. G.: Clostridial infection in a horse J. Am. Vet. Med. Assoc. 1979, 174, 725-726.

Corresponding author: Malwina Slowikowska DVM, PhD student, pl. Grunwaldzki 47, 50-366 Wroclaw, Poland; e-mail: malwina.slowikowska (a)upwr.edu.pl 